Article

\title{
Monitoring and Quantitative Human Risk Assessment of Municipal Solid Waste Landfill Using Integrated Satellite-UAV-Ground Survey Approach
}

\author{
Shuai Zhang ${ }^{1}$, Yunhong Lv ${ }^{1}{ }^{\oplus}$, Haiben Yang ${ }^{2}$, Yingyue Han ${ }^{1}{ }^{\circledR}$, Jingyu Peng ${ }^{1}$, Jiwu Lan ${ }^{1}$, Liangtong Zhan ${ }^{1}$, \\ Yunmin Chen ${ }^{1}$ and Bate Bate ${ }^{1, *}$ \\ 1 MOE Key Laboratory of Soft Soils and Geoenvironmental Engineering, Zhejiang University, \\ Hangzhou 310058, China; zhangshuaiqj@zju.edu.cn (S.Z.); lvyunhong@zju.edu.cn (Y.L.); \\ yingyuehan@zju.edu.cn (Y.H.); jingyupeng1996@zju.edu.cn (J.P.); lanjiwu@zju.edu.cn (J.L.); \\ zhanlt@zju.edu.cn (L.Z.); chenyunmin@zju.edu.cn (Y.C.) \\ 2 Hangzhou Environmental Group Co., Ltd., Hangzhou 310022, China; yanghaiben163@163.com \\ * Correspondence: batebate@zju.edu.cn
}

Citation: Zhang, S.; Lv, Y.; Yang, H.; Han, Y.; Peng, J.; Lan, J.; Zhan, L.; Chen, Y.; Bate, B. Monitoring and Quantitative Human Risk Assessment of Municipal Solid Waste Landfill Using Integrated Satellite-UAV-Ground Survey Approach. Remote Sens. 2021, 13, 4496 https://doi.org/10.3390/rs13224496

Academic Editors: Mi Wang, Hanwen Yu, Jianlai Chen and Ying Zhu

Received: 2 October 2021

Accepted: 8 November 2021

Published: 9 November 2021

Publisher's Note: MDPI stays neutral with regard to jurisdictional claims in published maps and institutional affiliations.

Copyright: (c) 2021 by the authors. Licensee MDPI, Basel, Switzerland. This article is an open access article distributed under the terms and conditions of the Creative Commons Attribution (CC BY) license (https:// creativecommons.org/licenses/by/ $4.0 /)$.

Abstract: Landfills are the dominant method of municipal solid waste (MSW) disposal in many developing countries, which are extremely susceptible to failure under circumstances of high pore water pressure and insufficient compaction. Catastrophic landfill failures have occurred worldwide, causing large numbers of fatalities. Tianziling landfill, one of the largest engineered sanitary landfills in China, has experienced massive deformation since January 2020, making early identification and monitoring of great significance for the purpose of risk management. The human risk posed by potential landfill failures also needs to be quantitatively evaluated. The interferometric synthetic aperture radar (InSAR) technique, unmanned aerial vehicle (UAV) photogrammetry, and ground measurements were combined to obtain landfill deformation data in this study. The integrated satellite-UAV-ground survey (ISUGS) approach ensures a comprehensive understanding of landfill deformation and evolution. The deformation characteristics obtained using the InSAR technique and UAV photogrammetry were analyzed and compared. A close relationship between the most severe mobility events, precipitation episodes, and was observed. Based on early hazard identification using ISUGS, a quantitative risk assessment (QRA) method and F-N curves were proposed, which can be applied to landfills. The comparison showed that ISUGS allowed a better understanding of the spatial and temporal evolution of the landfill and more accurate QRA results, which could be as references for local governments to take effective precautions.

Keywords: InSAR; UAV photogrammetry; early identification; risk analysis; risk management; F-N curve

\section{Introduction}

Municipal solid waste (MSW) is the most complex solid waste stream, which is usually disposed by landfilling [1,2]. With the acceleration of urbanization and the growth of the urban population, the production of MSW has rapidly increased in recent decades. Landfills are the dominant MSW disposal method in China, which are prone to fail in the rainy season. Failure results in severe pollution to the environment and threaten the lives and properties of people in the surrounding area once the failure occurs [3,4]. Landfill failures have frequently occurred all over the world in recent years (Table 1). 
Table 1. Review of MSW landfill failures worldwide over the past decades.

\begin{tabular}{|c|c|c|c|c|c|c|}
\hline Year & $\begin{array}{l}\text { Region and } \\
\text { References }\end{array}$ & $\begin{array}{l}\text { Elevation } \\
\quad(\mathrm{m})\end{array}$ & $\begin{array}{l}\text { Distance of } \\
\text { Flow (m) }\end{array}$ & $\begin{array}{l}\text { Volume of } \\
\text { Waste Flow } \\
\left(\mathrm{m}^{3}\right)\end{array}$ & Cause of Failure & Loss of Life \\
\hline 2017 & $\begin{array}{l}\text { Meethotamualla } \\
\text { (Sri Lanka) } \\
\text { Karunawardena } \\
\text { et al. (2019) }\end{array}$ & 50 & 280 & 72,342 & $\begin{array}{l}\text { Rainfall induced landfill } \\
\text { failure }\end{array}$ & 32 \\
\hline 2015 & $\begin{array}{c}\text { Shenzhen } \\
\text { (China) } \\
\text { Xu et al. (2017) }\end{array}$ & 111 & 1203 & 2.5 million & $\begin{array}{l}\text { Inadequate compaction, } \\
\text { insufficient dewatering } \\
\text { systems, and increased } \\
\text { steepening of the landfill } \\
\text { slopes }\end{array}$ & 82 \\
\hline 2013 & $\begin{array}{l}\text { Shiraz City } \\
\text { (Iran) } \\
\text { (Falamaki et al., } \\
\text { 2021) }\end{array}$ & 42 & 134 & 10,000 & $\begin{array}{l}\text { Pressurised water infiltrating } \\
\text { through the slope }\end{array}$ & 7 \\
\hline 2010 & $\begin{array}{l}\text { Patras (Greece) } \\
\text { G. et al. (2013) }\end{array}$ & 30 & 50 & 12,000 & $\begin{array}{l}\text { The failure was attributed to } \\
\text { poor landfill practices, the } \\
\text { steep inclination of the waste } \\
\text { mass, and the increased } \\
\text { percolation of rainfall water } \\
\text { in the waste mass (and } \\
\text { associated gas pressure } \\
\text { generation) due to the } \\
\text { absence of daily soil cover } \\
\text { and surface water } \\
\text { management system }\end{array}$ & 0 \\
\hline 2005 & $\begin{array}{l}\text { Badung } \\
\text { (Indonesia) } \\
\text { Lavigne et al. } \\
\quad(2014)\end{array}$ & 100 & 1000 & 2.7 million & $\begin{array}{l}\text { Rainfall induced landfill } \\
\text { failure }\end{array}$ & 147 \\
\hline 2000 & $\begin{array}{c}\text { Quezon City } \\
\text { (Philippines) } \\
\text { Huvaj-Sarihan } \\
\text { and Stark (2008) }\end{array}$ & 33 & 122 & 1.2 million & $\begin{array}{l}\text { Shear failure followed heavy } \\
\text { typhoon rains }\end{array}$ & 330 \\
\hline 1997 & $\begin{array}{c}\text { Bogota } \\
\text { (Columbia) } \\
\text { Blight (2008) } \\
\text { Caicedo et al. } \\
\quad(2002)\end{array}$ & 80 & 500 & 1.5 million & $\begin{array}{l}\text { The pore pressure was the } \\
\text { main factor responsible for } \\
\text { the instability of the landfill }\end{array}$ & 0 \\
\hline 1997 & $\begin{array}{l}\text { Durban (South } \\
\text { Africa) } \\
\text { Blight (2008) }\end{array}$ & 45 & 80 & 180,000 & $\begin{array}{c}\text { The liquids were obviously } \\
\text { accumulating in the waste } \\
\text { body and building up a head } \\
\text { of pore pressure }\end{array}$ & 0 \\
\hline 1993 & $\begin{array}{l}\text { Istanbul } \\
\text { (Turkey) } \\
\text { Kocasoy and } \\
\text { Curi (1995) }\end{array}$ & 40 & 60 & 15,000 & $\begin{array}{c}\text { Suddenly applied additional } \\
\text { disturbing force and the } \\
\text { winter rain triggered the } \\
\text { failure }\end{array}$ & 39 \\
\hline 1977 & $\begin{array}{c}\text { Sarajevo } \\
\text { (former } \\
\text { Yugoslavia) } \\
\text { Blight (2008) }\end{array}$ & 130 & 1000 & 200,000 & $\begin{array}{l}\text { Probably resulting from } \\
\text { large quantities of winter } \\
\text { rain infiltration into the } \\
\text { uncompacted } \\
\text { and uncovered waste }\end{array}$ & 0 \\
\hline
\end{tabular}

Due to the high compressibility of the MSW, landfills undergo continuous deformation in the process of landfilling and even after a landfill site is closed. Thus, monitoring the deformation process and quantitatively assessing landfill sites are essential for controlling their risks, calling for both spatial and temporal measurements and requiring continuous assessment of the extent and rate of deformation, as well as changes in the surface topog- 
raphy. Conventional ground measurements by geodetic tools and inclinometers usually provide high accuracy but also have limitations in terms of daily maintenance and the monitoring of macro-scale sites. Interferometric synthetic aperture radar (InSAR), which is used to measure the phase differences between two SAR acquisitions, was demonstrated to be suitable for monitoring long-terms surface displacements in various fields over time, with large coverage in a time-efficient and labor-saving manner [5]. Recent studies on deformation monitoring using time series InSAR (TS-InSAR) have been successfully conducted on city subsidence, volcanic activities, earthquakes, and landslides [6-10]. Given that numerous new constellations of satellites have recently been launched, especially European Space Agency (ESA) Sentinel-1 satellites, rapidly updated high-quality images provided by the ESA have made it possible to monitor displacement [11,12].

If Sentinel-1 C-band SAR images are adopted, the observable deformation range will be within $2.8 \mathrm{~cm}$ [13]. Although the important deformation and evolution information for landfills can be obtained from InSAR, the measurement precision is affected by decorrelation caused by spatial distribution, temporal intervals, single-look directions, and atmospheric delay $[14,15]$. The development of unmanned aerial vehicle (UAV) photogrammetry has allowed researchers to obtain high-resolution orthophoto maps and digital surface models (DSMs) in a more flexible way compared to InSAR. The capacity of UAV has been demonstrated in recent studies involving landslide monitoring [16-18]. Site images acquired by drones can be processed with structure from motion (SFM) methods and multi-image approaches to identify the geomorphological changes in hazardous bodies [18]. For the model used in this study, the planimetric RMS (root mean square) error is $4.1 \mathrm{~cm}$ and the altimetric RMS error is $5.7 \mathrm{~cm}$ for CPs (check points), which means the measurable deformation is above $5.7 \mathrm{~cm}$. It also has the disadvantages of weather sensitivity, relatively low accuracy, and deformation monitoring direction limitations. For ground surveys, a total station with an accuracy of $(1+2 \mathrm{ppm} \times$ Distance $\mathrm{mm})$ is used for measuring distance. Each monitoring technique has its own advantages and drawbacks, as well as its own measurable range (Table 2). The integrated satellite-UAV-ground survey approach to landfill monitoring has rarely been used, especially for landfills that are still in operation. here, we leverage the complementarity of the InSAR technique, UAV photogrammetry, and ground measurements in order to reveal both the deformation monitoring sensitivity and landfill site risks.

Table 2. Comparison of the satellite, UAV, and ground survey techniques used in this paper.

\begin{tabular}{|c|c|c|c|c|}
\hline $\begin{array}{l}\text { Monitoring } \\
\text { Method }\end{array}$ & $\begin{array}{c}\text { Observable } \\
\text { Deformation } \\
\text { Direction }\end{array}$ & $\begin{array}{c}\text { Observable } \\
\text { Deformation } \\
\text { Range }\end{array}$ & Advantages & Disadvantages \\
\hline InSAR technique & $\begin{array}{c}\text { LOS (Line Of } \\
\text { Sight) }\end{array}$ & $\leq 2.8 \mathrm{~cm}$ & $\begin{array}{c}\text { High-precision, } \\
\text { large coverage, } \\
\text { time-efficient. } \\
\text { labor-saving }\end{array}$ & $\begin{array}{c}\text { Decorrelations } \\
\text { caused by spatial } \\
\text { distribution, } \\
\text { temporal intervals, } \\
\text { single-look } \\
\text { directions, and } \\
\text { atmospheric delay; } \\
\text { difficulties in } \\
\text { solving deformation } \\
\text { direction }\end{array}$ \\
\hline $\begin{array}{l}\text { UAV photogram- } \\
\text { metry }\end{array}$ & Vertical & $\geq 5.7 \mathrm{~cm}$ & $\begin{array}{c}\text { Flexible, } \\
\text { macro-scale } \\
\text { coverage, } \\
\text { labor-saving }\end{array}$ & $\begin{array}{l}\text { Weather-sensitive, } \\
\text { relatively low } \\
\text { accuracy, } \\
\text { deformation } \\
\text { monitoring direction } \\
\text { limitations }\end{array}$ \\
\hline $\begin{array}{c}\text { Ground } \\
\text { measurements }\end{array}$ & $\begin{array}{l}\text { Vertical and } \\
\text { horizontal }\end{array}$ & $1-2 \mathrm{~mm}$ & $\begin{array}{l}\text { High-precision } \\
\text { and stable }\end{array}$ & $\begin{array}{l}\text { High cost, small } \\
\text { coverage, } \\
\text { labor-intensive }\end{array}$ \\
\hline
\end{tabular}


Landfill failures have caused numerous casualties worldwide (Table 1). The causes and consequences of landfill failures are somewhat uncertain. Risk analyses and assessments have become important in addressing inherent uncertainty relating to slope failures in recent years $[19,20]$. Most studies have focused on natural soil slopes rather than artificial slopes in MSW dumps [20,21]. The use of an effective risk assessment method and acceptable risk criteria for landfill failures is important for the decisions made by stakeholders and local governments.

Landfills in operation require constant monitoring and a quantitative risk assessment (QRA) to evaluate the hazards and consequences of potential failures. This study aims to propose an integrated monitoring method for a landfill that is in operation and to prove its effectiveness by obtaining better recognition and analysis results for the deformation characteristics of the landfill site. The QRA method is used to calculate the human risk in the landfill based on ISUGS. In this paper, a case study is conducted for the Tianziling MSW landfill in Hangzhou, China, to illustrate the applicability of the methods. In Section 2, we present the historical and current situation at the study site. The theory for ISUGS and QRA is presented in Section 3, and the observed results are presented in Section 4. The paper finishes with a discussion of the findings and some of the major conclusions.

\section{Study Area}

Tianziling landfill, one of the largest engineered sanitary landfills in China, was built in the Qinglongwu Valley in Hangzhou City (Figure 1). Since it was put into use in 1991, about 20 million tons of domestic MSW have been dumped. The remote sensing images from 2000 to 2021 clearly reveal the evolution of the landfill. It can be seen in Figure 1 that landfill work has been continuously carried out, and the surrounding supporting facilities and buildings have increased each year, as shown in Figure 2.



Figure 1. Location and topography of study site: (a) China and Zhejiang province, whereby the red box shows the coverage of the Sentinel-1 images; (b) DEM of Hangzhou City; (c) UAV 3D model of study site, whereby the white arrow indicates the vertical anti-seepage curtain. 


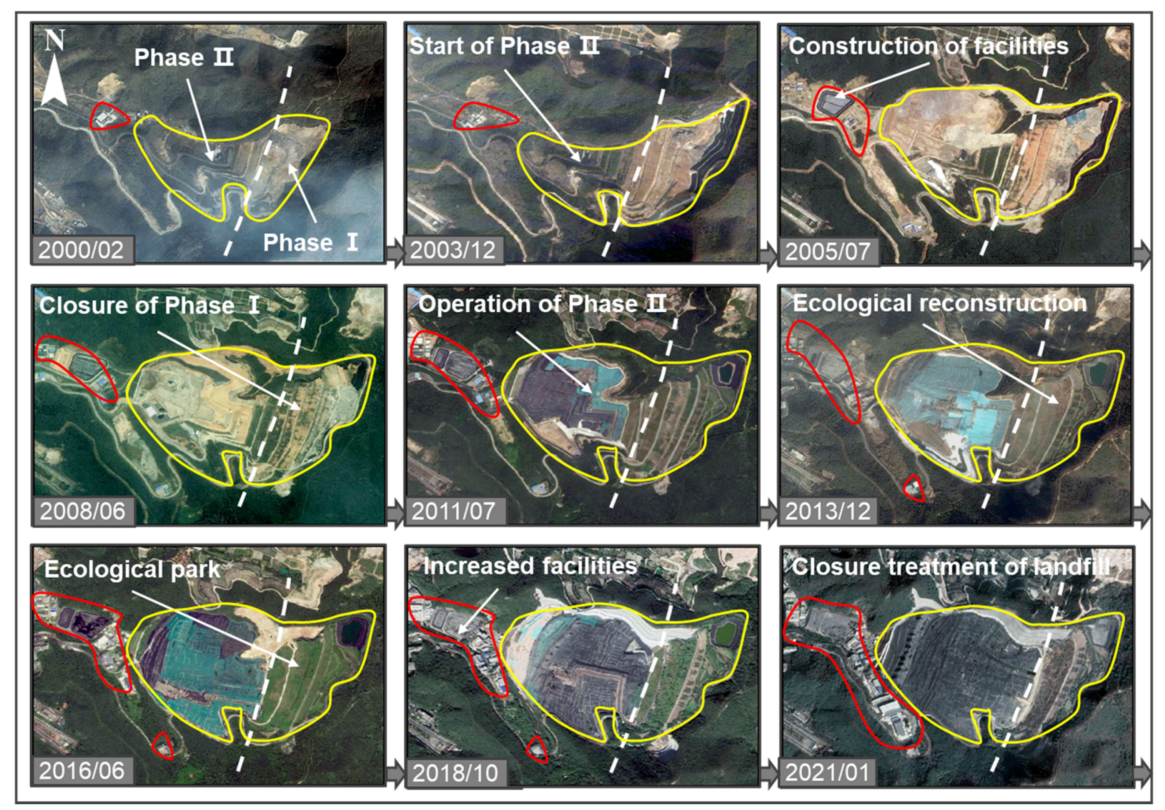

Figure 2. Evolution of Tianziling MSW landfill based on satellite remote sensing images. The yellow lines indicate the boundaries of the landfill and the red lines show the development of construction facilities around the landfill.

The landfill is composed of phase I and phase II areas (Figures 2 and 3). The phase I landfill covers an area of 48 hectares. The aerobic-anaerobic landfill method (AALM), inspired by wastewater treatment technology, was adopted in the Tianziling landfill. Vertical curtain grouting anti-seepage technology was used to prevent leachate from polluting the downstream (Figure 1). Until its closure in 2007, more than 9 million tons of MSW had been landfilled and an ecological park had been built. The phase II landfill, which is still in use, is located downstream of the first landfill, extending $440 \mathrm{~m}$ westwards and covering an area of 96 hectares, with a maximum design elevation of $165 \mathrm{~m}$ and a total storage capacity of 22.02 million $\mathrm{m}^{3}$. Until July 2021, more than 4000 tons of MSW have been processed in the phase II landfill every single day, while the top elevation slope of the MSW dump has reached about $120 \mathrm{~m}$. An aerial view of the landfill site is shown in Figure 3, which also indicates the dumping areas, sludge pits, and on-site monitoring points.

Due to the rapid landfill of MSW, net deformation has been monitored on-site since January 2020, with the maximum displacement velocity and accumulative deformation of the landfill body exceeding $10 \mathrm{~mm} / \mathrm{d}$ and $8 \mathrm{~m}$, respectively (Figure 4). Local failure in the upper area of the backpressure body has obviously occurred, while cumulative leachate and water outbursts with sludge have occurred in the southwest corner of the landfill (Figure 5). The power generation company and resource utilization division are located in the downstream area of the dam body. Once a large sliding event occurs, this may cause serious personnel and property losses. As such, it is necessary to carry out a stability assessment of the phase II landfill slope under extreme conditions and to calculate the potential risk of landfill failure. 




Figure 3. Aerial view of site conditions. The monitoring period for deformation monitoring points S1, S2, S3, S6, S7, and S10 was form March 2019 to July 2020, while that of monitoring points S4, S5, S8, and S9 was from July 2020 to November 2020. The white line I-I' indicates the profile used for the instability probability analysis, while the white dashed line indicates the boundary of phase I and phase II projects. The red angle in point V shows the viewing direction during field investigation.

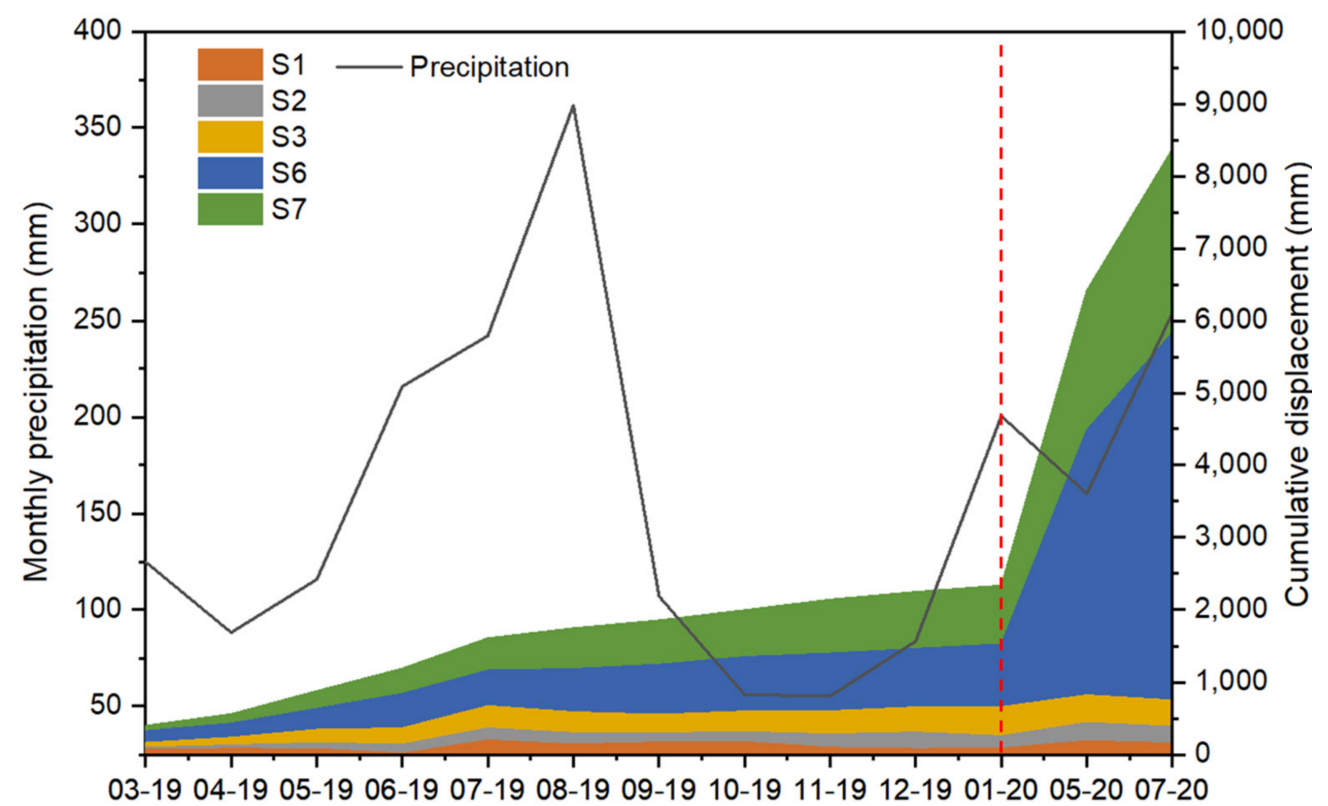

Figure 4. Ground measurements of horizontal displacement from March 2019 to July 2020. The red dashed line indicates the massive deformation event. The locations of the deformation points are shown in Figure 4. 

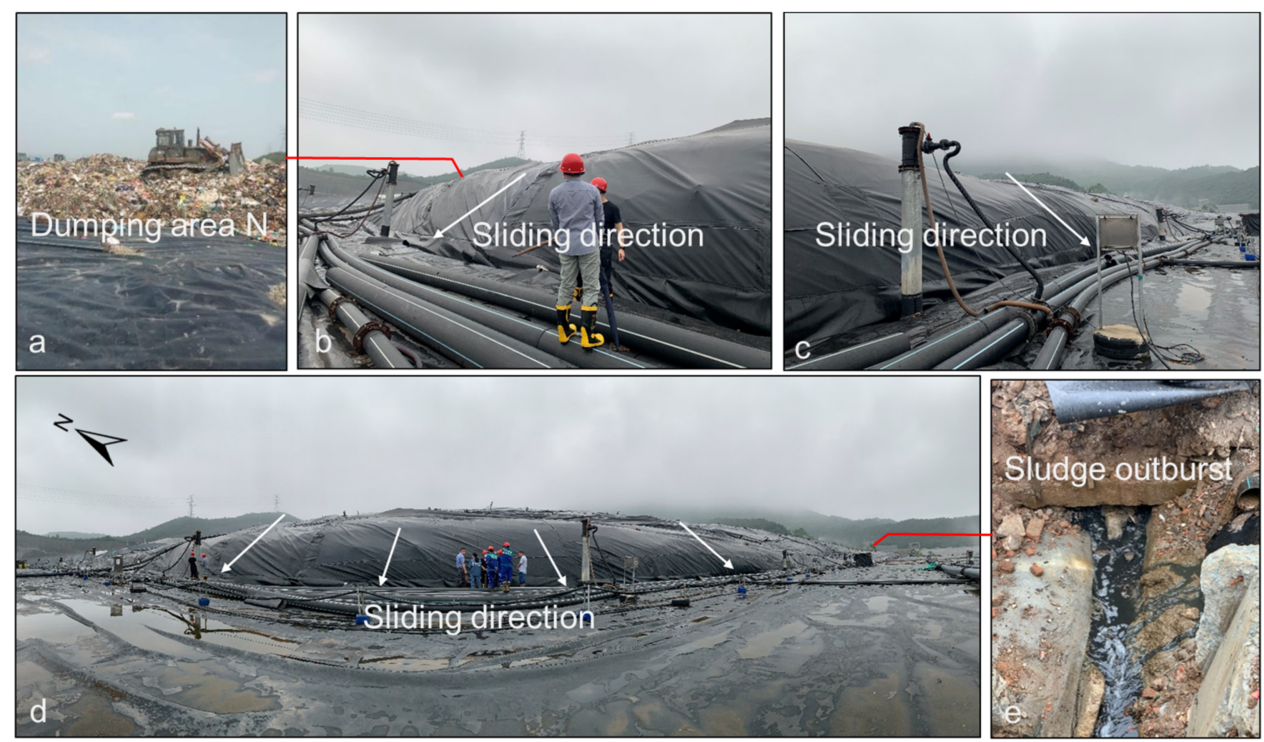

Figure 5. Images taken during field investigation: (a) dumping area $\mathrm{N}$; (b-d) the sliding direction of the waste dump shown by white arrows, the viewing direction shown in Figure 3; (e) observed leachate and water outbursts with sludge in the southwest corner of the landfill, whereby the red lines indicate the positions of $(\mathbf{a}, \mathbf{e})$.

\section{Materials and Methods}

Multi-source information fusion using the InSAR technique, UAV photogrammetry, and ground measurements can help in identifying risks and monitoring deformation in the field. A QRA method was adopted to analyze the potential human loss due to landfill failure based on Monte Carlo simulation, considering the spatial variability of the MSW's geotechnical parameters. Figure 6 shows the research target and technical route for this paper.

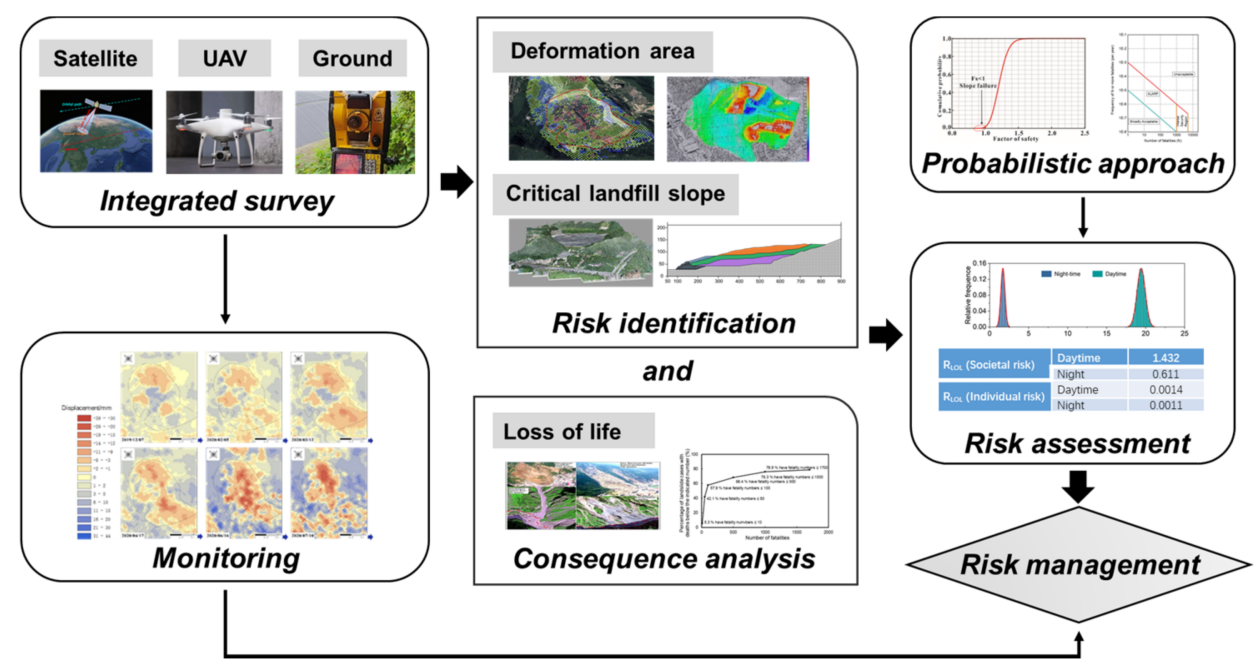

Figure 6. The methodology framework used in this paper.

\subsection{Ground Measurements}

Mainly relying on total station data, a ground-based geodetic technique was adopted to monitor the deformation of the landfill surface. The ground control points were located in the active deformation area near the landfill dam, which were divided into two groups according to the different monitoring periods (Figure 3). 


\subsection{InSAR Technique}

Sentinel 1A satellite data in interferometric wide (IW) swath mode have been successfully used for deformation time series comparisons [5,11]. As shown in Table 3, a total of 32 scenes of sentinel-1 satellite data [22] from November 2019 to November 2020 with a temporal baseline of 12 days were selected to analyze the time series deformation of Tianziling landfill via differential interference. The SAR scenes are shown in ascending orbit, covering the area shown in Figure 1. Precise Orbit Ephemerides (European Space Agency) and 1-arc-second resolution external SRTM DEM (Shuttle Radar Topography Mission Digital Elevation Model) were used to remove the terrain phase and orbit error. The analyses were performed using the small baseline subset (SBAS) method, which is based on coherent targets (CTs), whereby neighbouring pixels in images have similar backscattering characteristics $[23,24]$.

Table 3. Main parameters of Sentinel-1 SAR datasets.

\begin{tabular}{cc}
\hline Radar Satellite & Sentinel-1 \\
\hline Time & November 2019-November 2020 \\
Orbital direction & Ascending \\
Band & $\mathrm{C}$ \\
Radar wavelength & $5.6 \mathrm{~cm}$ \\
Spatial resolution & $5 \times 20 \mathrm{~m}$ \\
Revisit period & 12 days \\
Polarization mode & VV \\
Incidence angle & $39.3^{\circ}$ \\
\hline
\end{tabular}

The SBAS method enabled us to reduce spatial and temporal decorrelation by generating multi-master interferogram pairs among all the SAR scenes, which were registered and resampled separately, then the pairs were divided into different short baseline sets. Individual interferograms were adopted with a temporal baseline and spatial threshold of less than 120 days and $2 \%$, respectively. Considering that the study site is in a rural area, a filtering process was performed to remove noise caused by various error sources, according to the coherence of which the threshold was set to 0.15 [15]. These filtered interferograms were separated into high-quality and low-quality pairs, whereby the latter showed poorer correlations of interference fringes and were discarded to avoid interference with results. A further analysis method was developed using a minimum cost flow algorithm for phase unwrapping. Deformation maps of the LOS direction were created based on singular value decomposition and the least squares method after removing the atmospheric delay phase via high-pass temporal and low-pass spatial filtering [25].

\subsection{UAV Photogrammetry}

LOS deformation could be clearly observed in parts of the landfill using the specific InSAR technique. However, the decomposition of deformation along the LOS direction into the real deformation direction is limited when multi-tracking SAR data are not available [26]. UAV photogrammetry has a good sense of vertical deformation and higher spatial resolution at the monomer scale for single landfill events [16-18]. The combined use of InSAR and UAV better supports monitoring. Two photogrammetric outputs were used, dated July 2020 and November 2020. The acquisition flights of the two campaigns were carried out with a multi-rotor UAV DJI Phantom 4 series. The UAV specifications are shown in Table 4. 
Table 4. DJI Phantom 4A specifications.

\begin{tabular}{cc}
\hline Weight & $1380 \mathrm{~g}$ \\
Maximum horizontal flight speed & $72 \mathrm{~km} / \mathrm{h}$ \\
Maximum allowable wind speed & $10 \mathrm{~m} / \mathrm{s}$ \\
Maximum flight time & $28 \sim 30 \mathrm{~min}$ \\
Satellite positioning module & GPS / GLONASS dual mode \\
Controllable rotation range & Pitch: $-90^{\circ}$ to $+30^{\circ}$ \\
Image sensor & $1 / 2.3$ inch CMOS \\
& 12.4 million effective pixels \\
\hline
\end{tabular}

Before the image capturing work, ground control points (GCPs) were defined first, referenced to the relatively stable area, and evenly distributed throughout the site (Figure 3). The coordinates of GCPs were processed using Trimble Systems differential global navigation satellite system (GNSS) techniques, the measurement accuracy of which was $0.05 \mathrm{~m}$ in the horizontal direction and $0.08 \mathrm{~m}$ in the vertical direction. Simultaneously, some GCPs were used as CPs in order to verify the quality of the image orientation. After alignment using the SFM technique, DSMs and ortho-images of the two flights were generated. Due to the vegetation cover, the derived DSMs do not represent the actual elevation model, as mentioned in previous research [25]. The areas covered with vegetation were discarded when analyzing the deformation of the landfill. These were located around the landfill. The use of a consistent coordinate system and accurate registration is important in generating differential elevations of two consecutive DSMs acquired from the two flights.

\subsection{Quantitative Risk Assessment}

InSAR and UAV photogrammetry helped us to identify the potential failure area. In this area, the profile with the steepest slope was locked for stability calculation. The human risk posed by the potential failure of the landfill can be quantified based on QRA [27]. Two risk formats are presented here, one being societal risk and the other being individual risk, relating to the risk to the entire population in a large area and the risk to a single person in a specific location, separately [21]. The annual potential loss of life (societal risk), $R_{\mathrm{LOL}}$, is defined as [28]:

$$
R_{L O L}=\left[P_{\mathrm{f}} \times P_{T: L} \times P_{S: T}\right] \times\left[V_{D: S} \times E\right]
$$

where $P_{\mathrm{f}}$ is the probability of landfill failure; $P_{T: L}$ is temporal probability, which is the probability of the landfill failure materials reaching the area where people are located; $P_{S: T}$ is the spatial probability that people will be exposed to the area affected by the landfill failure; $V_{D: S}$ is the human vulnerability (i.e., the chance of people losing their lives when they are impacted by the landfill failure); $E$ is the element at risk, which is the number of humans at risk due to failure in the study area. The product of the first three terms in the formula is the hazard, while the product of the last two terms is the consequence.

The individual risk of loss of life, $R_{D I}$, is a useful definition for the individual element (e.g., one person life), which can be calculated from:

$$
R_{D I}=\left[P_{L} \times P_{T: L} \times P_{S: T}\right] \times V_{D: S}
$$

\section{Results}

Landfill deformation results acquired by ISUGS were analyzed and compared with each other quantitatively. Massive deformation was identified, which provided targets for landfill failure hazard assessments. The evolution of the landfill dump mobility was revealed using deformation time series analysis for waste management and precautions.

\subsection{InSAR Technique}

The deformation along the LOS direction around the landfill site is shown in Figure 7a. The unwrapped interferograms showed the interference phase change, which indicated ground deformation (Figure $7 \mathrm{~b}$ ). The spatial distribution of the CTs superimposed onto the 
landfill site map downloaded from Google Earth is shown (Figure 7c), whereby positive values indicate the motion toward the satellite along the LOS direction and negative values correspond to motion opposite to the LOS direction. The maximum deformation areas with an average velocity of $-72 \mathrm{~mm} /$ year were located in the areas where MSW was dumped and with sludge pits underneath. Specifically, large deformation caused by frequent engineering activities was also observed in part of the back pressure body (Figures 3 and 7). Small deformation areas with an average velocity of $10-15 \mathrm{~mm} /$ year are distributed along the landfill boundary.

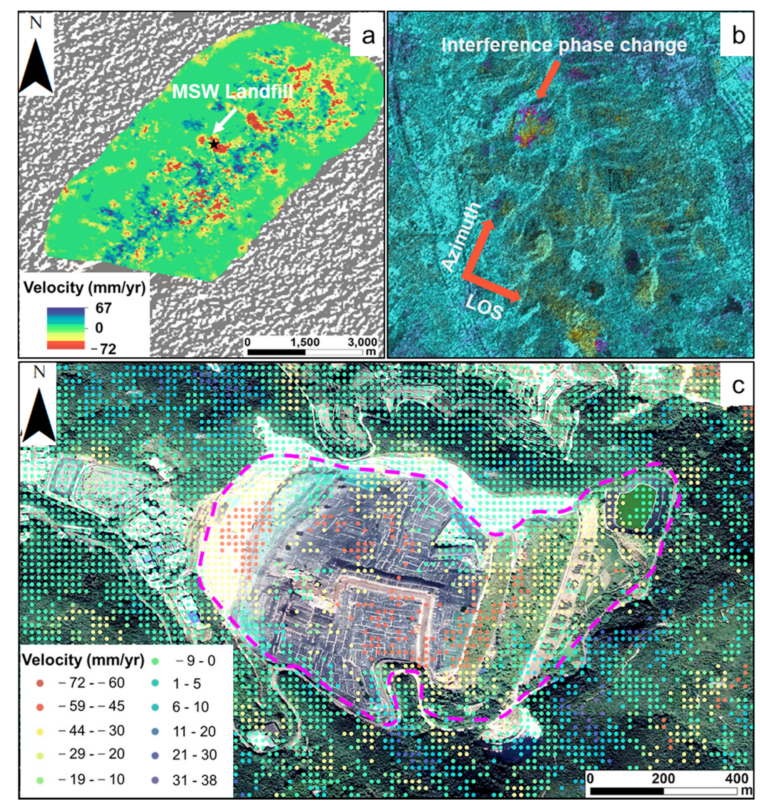

Figure 7. LOS deformation map from SBAS analysis: (a) deformation map for the surrounding area of the landfill, where the black pentagram indicates the landfill location; (b) phase change of interferogram; (c) deformation map of Tianziling landfill, where the purple dashed line indicates the landfill boundary.

The deformation rate maps were compared with total station measurements by projecting the LOS deformation onto the vertical and horizontal directions using an incidence angle. Specifically, the horizontal deformation projection was biased to the east-west direction, as seen through the investigation of the site topography. Both types of measurement were relative in time and space. For temporal distinction, the spline interpolation was applied to match the two measurements. For space deviation, the nearest points between two measurements were chosen. Four of the 6 and 3 of the 4 monitoring points demonstrated linear correlations in period 1 and period 2, respectively, as shown in Figure 8 . The projection of InSAR measurements onto the vertical and horizontal directions was based on the assumption that the deformation in the other direction was 0 . However, the assumption ignored the north-south deformation and only showed the correlation between LOS deformation and deformation in vertical and east-west directions. The sensitivity of the InSAR measurements of the deformation in horizontal and vertical directions was exploited by comparing the $\mathrm{R}^{2}$ values of linear fitting lines. In monitoring period $1, \mathrm{~S} 1, \mathrm{~S} 2$, and S10 showed a greater subsidence trend than horizontal deformation trend, whereas S6 indicated a greater deformation trend in the horizontal direction, as can be seen in Figure 8a,c. This difference was mainly due to the different positions in the landfill site. S1 and S2 are both located near the back pressure body of the landfill, which plays a significant role in blocking the slope forward (Figure 3). The deformation is mainly subsidence induced by the mechanical compression and biochemical decomposition. S6 is located in the MSW body, with ongoing dumping operations in which the horizontal deformation is more significant. Meanwhile, S10 is located in the phase I landfill, which has 
been sealed and tends to subside due to biological decomposition and mechanical creep (Figures 3 and 7). For period 2, the correlation of the two measurements was relatively low when compared to period 1 . This might have been induced by the close distance to the dumping area leading to more temporal decoherence of InSAR measurements. As shown in Figure 8b,d, the good correlation when monitoring points S4, S5, and S8 showed a greater horizontal deformation trend than subsidence trend. This was due to horizontal extrusion from the dumping area to the downstream area (Figure 3).
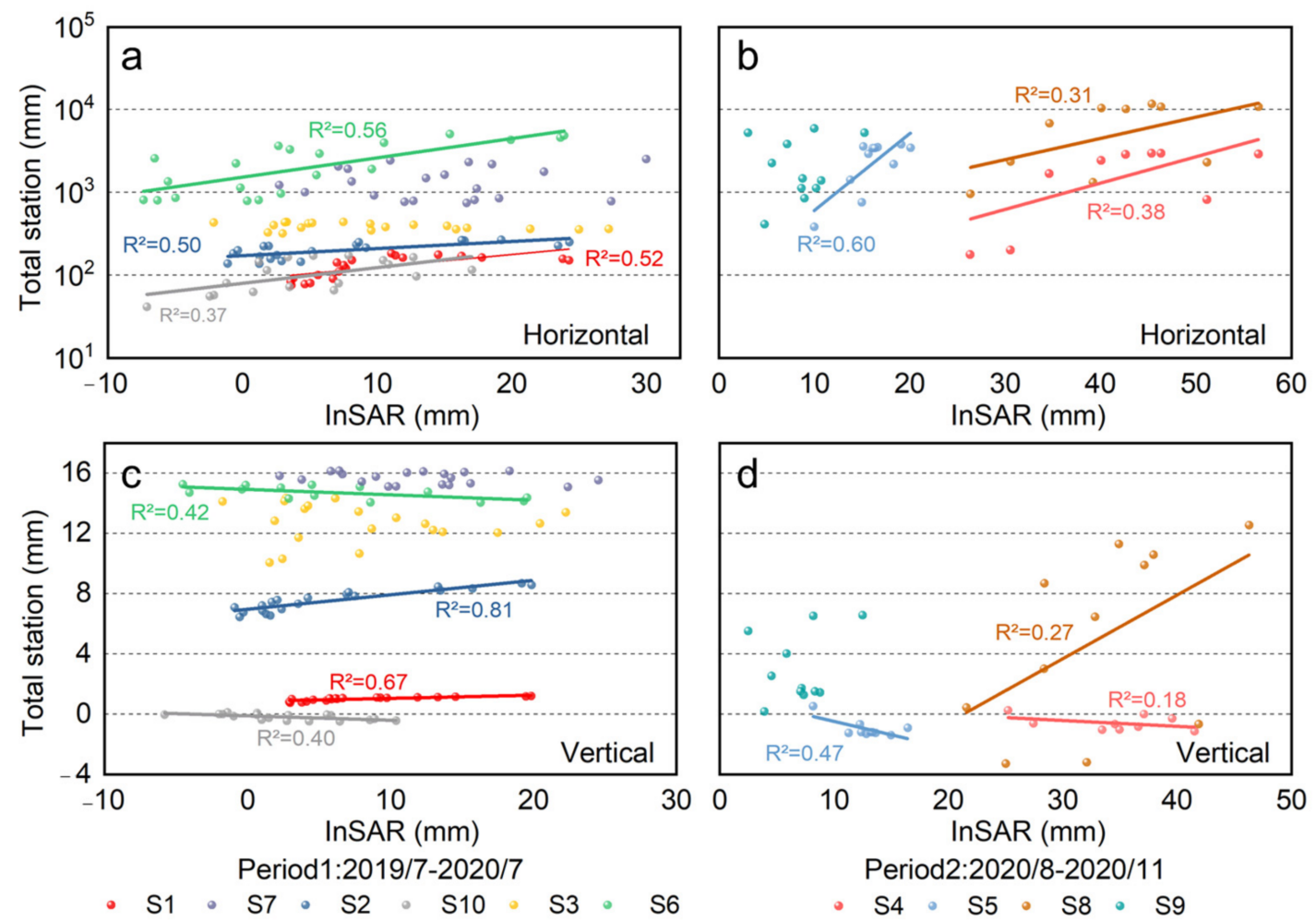

Figure 8. Comparison of InSAR interferometry and total station monitoring results. The comparison was conducted through two different monitoring periods. $(\mathbf{a}, \mathbf{b})$ Comparison of the horizontal deformation. (c,d) Comparison of the vertical deformation, whereby positive values represent uplift and westward deformation and negative values represent settlement and eastward deformation. The locations of the monitoring points are shown in Figure 3.

Monitoring records for S1, S2, S5, S6, and S10 showed higher coherence between InSAR and ground measurements. The projected displacement time series plotted in Figure 9 show rather changeable displacement trends. Monthly precipitations data collected from GES DISC (Goddard Earth Sciences Data and Information Services Center) are also shown. Data obtained at S1, S2, and S10 indicated a subsidence trend, while S5 and S6 showed a horizontal deformation trend. From temporal perspectives, the landfill has been showing a trend of continuous deformation growth since January 2020, which can be verified by the in situ data (Figure 5). The analysis demonstrated severe deformation trends on four occasions, each of which lasted for about a month, with displacements varying from $5 \mathrm{~mm}$ to over $20 \mathrm{~mm}$. These were recorded separately, in January-February, May-June, July-August, and October-November of 2020; every occasion was preceded by rainfall events 1 or 2 months before, with monthly rainfall exceeding $150 \mathrm{~mm}$. 


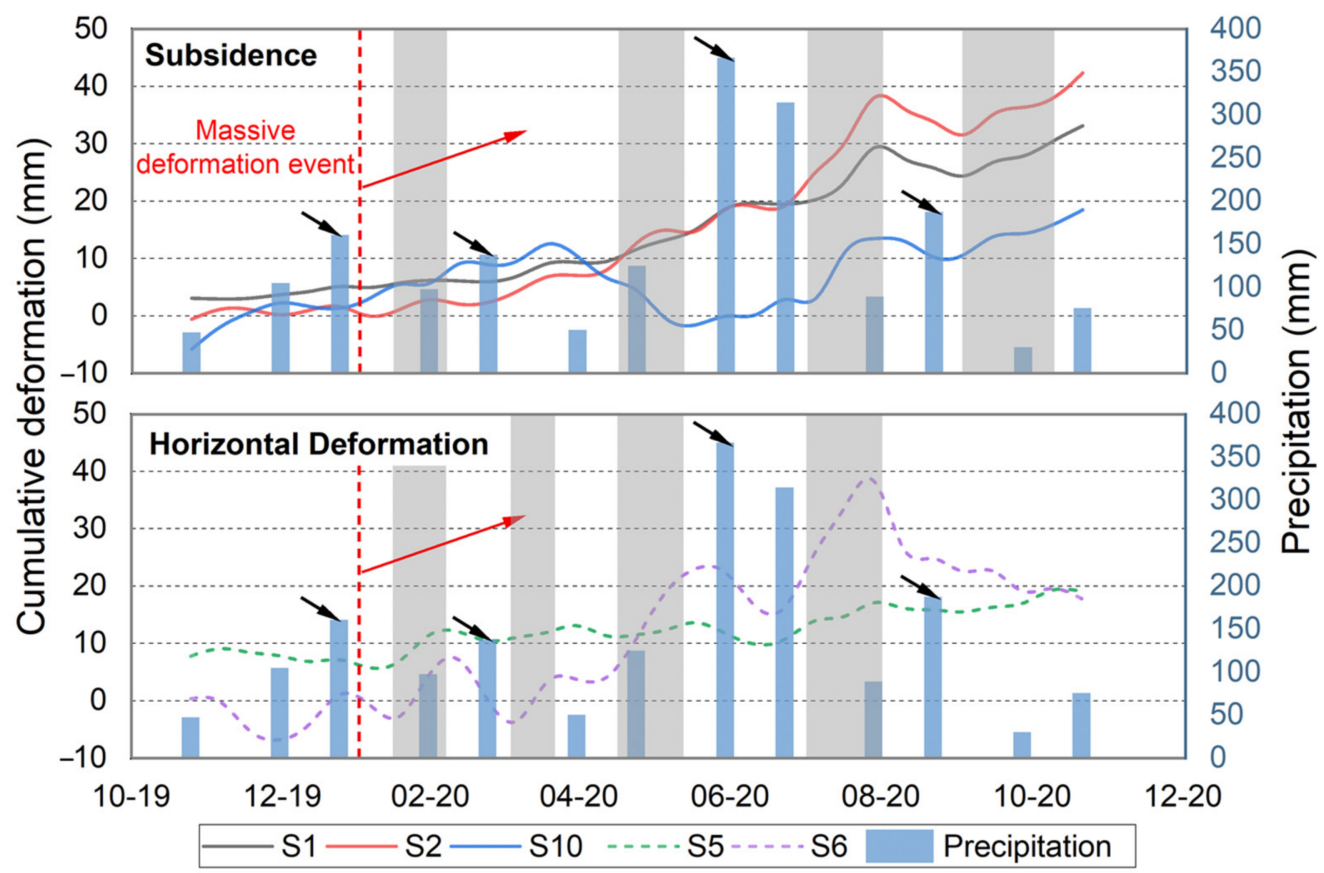

Figure 9. Relationship between cumulative deformation and monthly precipitation. The black arrows indicate 4 periods of peak precipitation, while the four gray columns represent the 4 maximum deformation gradient periods.

\subsection{UAV Photogrammetry}

The InSAR approach can detect long-term trends in landfill movement and behavior. UAV photogrammetry has the ability to observe vertical deformation over the short-term with high accuracy. It is necessary to combine UAV photogrammetry with InSAR and ground-based surveys to understand the migration of MSW materials in the landfill site.

Based on the elevation differences between the two DSMs, zones with elevation decreases and increases were analyzed. The dumping area was excluded to improve the accuracy of the deformation analysis. As shown in Figure 10, the area with displacement derived from UAV photogrammetry matched well with the interpretation of the InSAR data. The landfill site was divided into zone $A$, zone $B$, and zone $C$ for analysis, whereby the areas with subsidence and uplift intersected with each other. It can be observed that remarkable displacement was recorded around the two dumping areas with values close to $3 \mathrm{~m}$, followed by the south portion of zone B near the sludge pits and the north portion of zone A, with deformation reaching about $1.2 \mathrm{~m}$. The green area indicated no obvious deformation during the two flights. Furthermore, the mobility along the two profiles II-II ${ }^{\prime}$ and III-III' was analyzed to determine the MSW migration. Along the profile II-II', the subsidence area predominated in zone $\mathrm{A}$ and zone $\mathrm{C}$, with the maximum elevation changes ranging from 0.1 to $2.5 \mathrm{~m}$, showing a large magnitude of deformation between July 2020 and November 2020. The uplift area in zone B was due to the dumping work in dumping area N. Meanwhile, the MSW material in zone B constantly supplies zone A, which showed strenuous movement of MSW body. As for profile III-III', dumping work in dumping area $\mathrm{S}$ of zone $\mathrm{C}$ seemed to have little impact on zone A and zone B due to the timely MSW disposal operation on site. The MSW replenishment of zone A mainly comes from zone B, both of which showed similar elevation changes ranging from 0.1 to $1.3 \mathrm{~m}$. Moreover, the north part of zone B also showed a certain movement trend to the south side of area A due to the migration of MSW materials. This also explained the complex movement features of InSAR measurements obtained at monitoring point $\mathrm{S} 6$. The mobility of the whole landfill is shown in Figure 10a. 




Figure 10. UAV-derived vertical displacements: (a) uplift; (b) subsidence. The white dashed lines show the boundaries of zone A, zone B, and zone $\mathrm{C}$. The red arrows in (a) indicate the direction of landfill mobility. The red dashed lines in (b) represent the profile distribution used for cross-comparison between InSAR and UAV.

The vertical displacement rates obtained at S4 and S5 were $-3.91 \mathrm{~cm}$ and $2.29 \mathrm{~cm}$, which exceeded the confidence interval of the UAV photogrammetry $(5 \mathrm{~cm})$, meaning they could not be used for accuracy verification. UAV-derived vertical deformation rates at monitoring points $S 8$ and $S 9$ were $119 \mathrm{~cm}$ and $75 \mathrm{~cm}$, respectively, corresponding to in situ monitoring data values of $125.5 \mathrm{~cm}$ and $65.8 \mathrm{~cm}$. The deviation of UAV photogrammetry for all stations was less than $10 \mathrm{~cm}$, indicating superior performance for the UAV measurements. UAV-derived vertical deformation was also compared with InSAR monitoring data, as shown in Figure 11. Two longitudinal profiles, II-II' and III-III', which were drawn along the main direction of landfill mobility from zone $\mathrm{C}$ to zone $\mathrm{A}$, were adopted for comparison analysis. We did not seek to quantitatively match the millimetric resolution displacements obtained from InSAR and UAV photogrammetry, as both measurement types were relative in time and space. However, the total deformation trend for the two measurement types was compliant, except for some of the middle parts in profile II-II' (distance from 100 to 150 $\mathrm{m}$ ) and rear parts in both profile II-II' and III-III' (distance from 300 to $400 \mathrm{~m}$ ) due to InSAR monitoring defects. From a data integrity and simplicity perspective, the deformation results obtained from DSMs derived from UAVs are superior at the monomer-scale level than the results obtained from InSAR. The joint displacement records for both types of measurement can be used to reconstruct the deformation characteristics of the landfill and to help with the risk assessment.

\subsection{Analysis of Deformation Mechanism}

In terms of the spatial distribution, the deformation of S10 showed an opposite subsidence trend during the maximum rainy season from May to July as compared with S1 and S2, indicating different displacement evolution patterns for landfill phase I and phase II (Figure 9). In addition to the dumping work on site, mechanical compression and biochemical effects are the main mechanisms of ground deformation in Tianziling landfill. Mechanical compression is caused by the self-weight stress of the MSW body and the imposed load, which alter the pores filled with gas and water. The biochemical process is usually accompanied by the transformation of the material phase, in which the solid-phase degradable material is transformed into liquid-phase leachate and gasphase landfill gas [3,29-31]. Deformation occurs as solid-liquid-gas interaction processing within the landfill, which can be complicated and prolonged or can happen unexpectedly. Having been shut in 2007, the phase I landfill tends to be inactive in terms of mechanical compression and biochemical activity, showing a relatively stable deformation trend. 


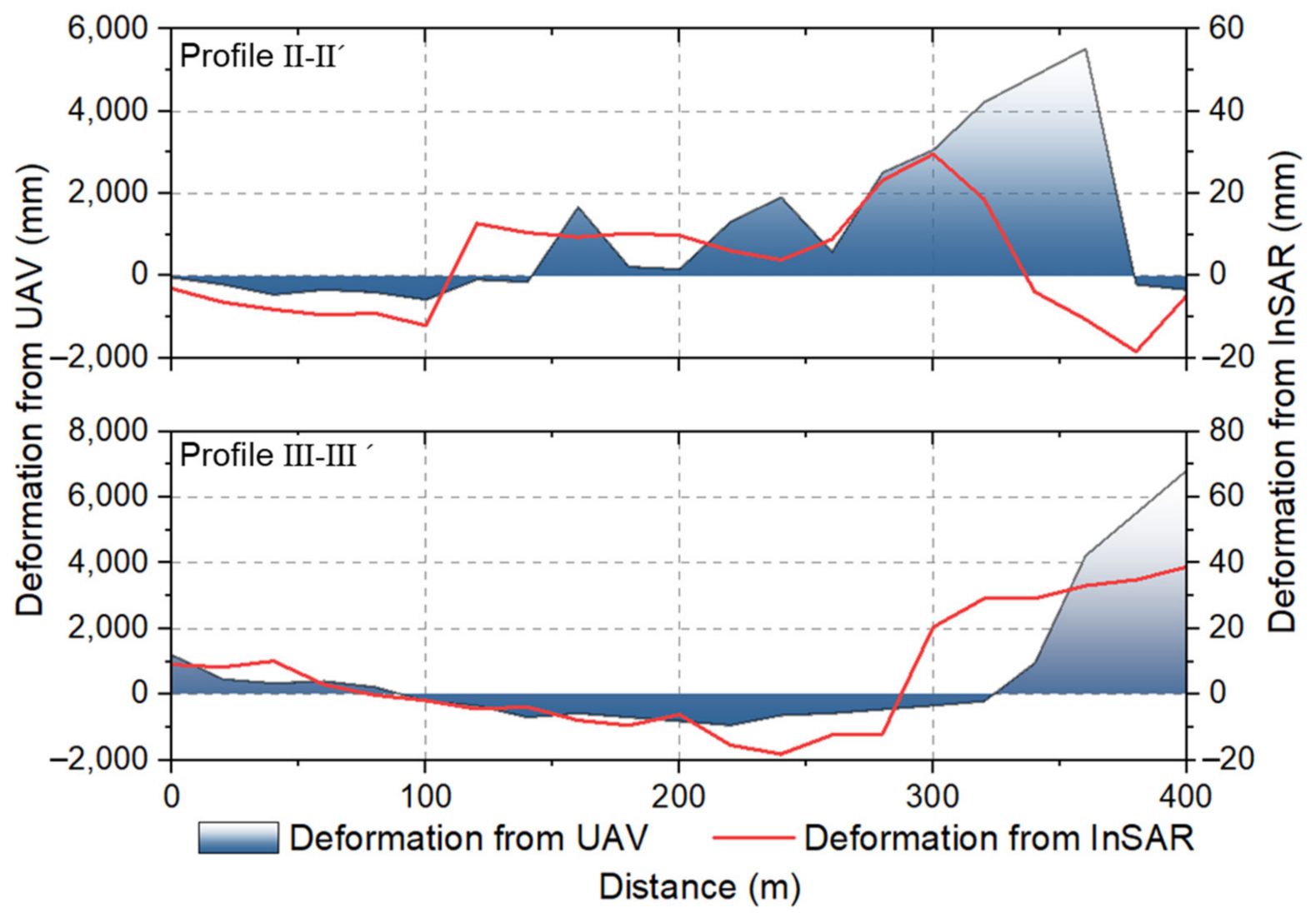

Figure 11. Comparison of InSAR interferometry and UAV photogrammetry results along the two profiles.

The high water content and rheology of sludge pits underneath zone B contribute to MSW migration from zone B to zone A along the profile III-III' (Figure 10), as leachate and water outbursts with sludge can be seen in the southwest landfill (Figure 6e). The fluid-like sludge transfers the vertical loading of waste into a lateral pressure of the same magnitude acting on the downstream waste slope. Additionally, some fluid-like sludge is squeezed into the surrounding waste body, as well as the interface between the waste and the underlying liner, leading to a decrease in the frictional strength [32].

Clearly, rainfall events had a strong influence on the landfill mobility. This may have been due to several reasons: (1) rainfall increases overburden stress leading to reorientation or distortion of MSW particles; (2) compression of the pore fluid; (3) increases in water content promote the decomposition of organic matter and the generation of methane. Notably, compared with the peak rainfall, the deformation gradient of the MSW body had a certain temporal lag of about a month (Figure 9).

\subsection{Quantitative Risk Assessment of Potential Landfill Failure}

Based on the ISUGS, a wide range of displacement rates from millimeters to meters were identified and measured, taking into account the changes and evolution observed in the landfill. As discussed before, heavy rainfall is the major cause of landfill or dumpsite failures. Landfill failure hazard, the major consequence of which is loss of life, requires more investigation using a risk analysis approach, especially in areas with frequent typhoons and abundant rainfall. A QRA of Tianziling landfill was conducted under two precipitation scenarios (Table 5) for rational decision making. 
Table 5. Description of two precipitation scenarios.

\begin{tabular}{cccc}
\hline $\begin{array}{c}\text { Precipitation } \\
\text { Scenario }\end{array}$ & Return Period & Rainfall Intensity & Additional Condition \\
\hline Scenario 1 & 50 years & $\geq 194 \mathrm{~mm} / \mathrm{d}$ & Effective drainage facilities \\
Scenario 2 & 100 years & $\geq 207 \mathrm{~mm} / \mathrm{d}$ & Failure of drainage facilities \\
\hline
\end{tabular}

\subsubsection{Determination of Failure Probability, $P_{\mathrm{f}}$}

In comparison to deterministic stability analyses, the probabilistic approach can consider geotechnical uncertainties in MSW. The failure probability of the landfill was determined by considering the uncertainties of shear strength parameters of MSW, i.e., the friction angle and cohesion. Monte Carlo simulation, one of the most popular probabilistic approaches, was first applied for the hazard assessment of landslides by Calvo and Savi [30] and was used here to calculate the probability distribution of the factor of safety (FOS). A slope will fail only if the FOS is lower than unity, which is the probability of failure $(\mathrm{P}(\mathrm{FOS}<1))$. Table 6 shows the mean and coefficient of variation $(\mathrm{COV})$ of the required data for MSW cohesion and friction angle probabilistic distributions, which were derived from values in the literature $[4,19]$ and technical code for geotechnical engineering of municipal solid MSW sanitary landfills [31].

Table 6. The geotechnical characteristics of the MSW landfill profile.

\begin{tabular}{ccccccc}
\hline \multirow{2}{*}{ Partition } & Depth $(\mathbf{m})$ & \multirow{2}{*}{$\begin{array}{c}\text { Unit Weight } \\
\left(\mathbf{k N} / \mathbf{m}^{3}\right)\end{array}$} & \multicolumn{2}{c}{ Cohesion $\mathbf{( k P a )}$} & \multicolumn{2}{c}{ Friction Angle $\left(^{\circ}\right)$} \\
\cline { 4 - 6 } & & 11.3 & Mean & COV & Mean & COV \\
\hline Shallow & $0-10$ & 12.5 & 15 & 0.15 & 12 & 0.3 \\
Middle & $10-30$ & 13.9 & 10 & 0.15 & 18 & 0.3 \\
Deep & Over 30 & & &
\end{tabular}

Previous research has shown that the friction angle and cohesion of the MSW follow normal and log-normal distributions, respectively $[18,19]$. The geotechnical parameters of MSW obtained using engineering analogies were calculated under two rainfall scenarios, i.e., return periods of 50 years and 100 years (Figure 12), which led to different water levels inside the MSW dump. Scenario 1 was established based on the measured water table data inside the dump while Typhoon Firework passing through Hangzhou. The maximum precipitation in some areas near the landfill was greater than $100 \mathrm{~mm} / 12 \mathrm{~h}$, representing an event with a probability of occurring once in 50 years [33]. Scenario 2 assumed an 100-year extreme rainstorm causing the ground water table inside the MSW dump to reach the surface when all drainage facilities failed. According to the deformation characteristics revealed by the satellite-UAV-ground survey, a profile (Figure 12) with severe deformation and instability risk was selected to analyze the probability of failure. The failure probability fluctuated greatly at first and tended to converge later as the simulation times increased. Considerably more iterations were required for calculation convergence under the scenario of low failure probability (Figure 13a). A total of 100,000 simulations were conducted in the calculation, which was adequate to obtain an accurate statistical response. As shown in Figure 13b, the FOS follows a normal distribution, which is consistent with the MSW parameter distribution. 


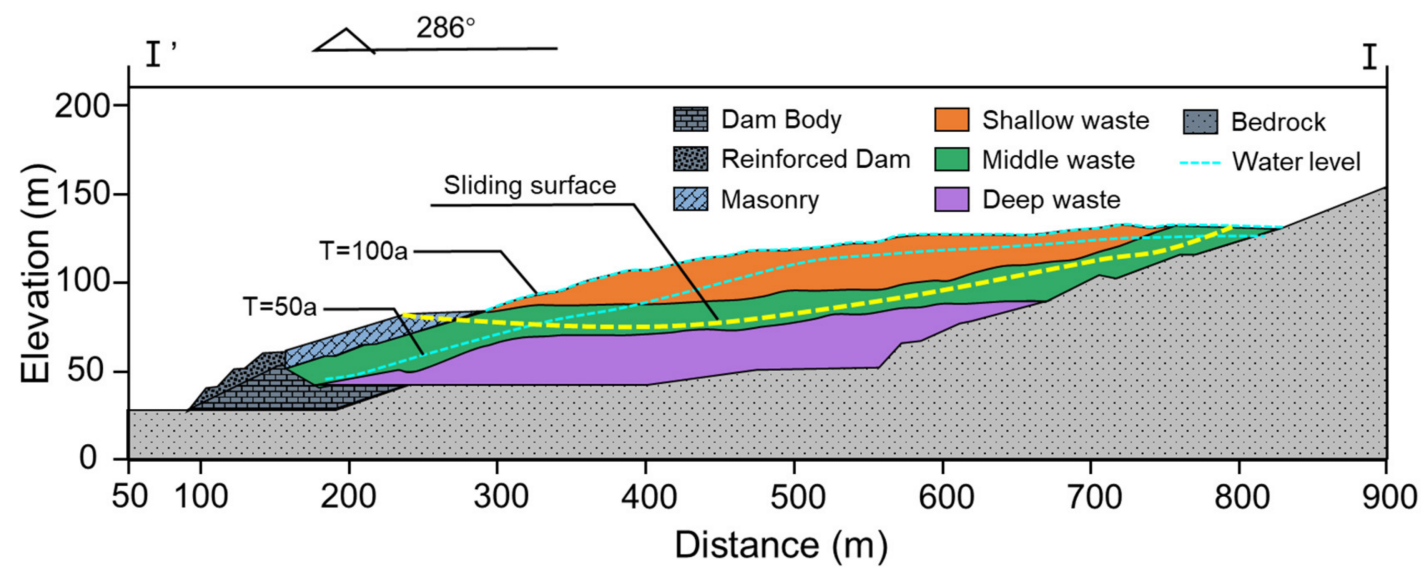

Figure 12. Longitudinal profile of the critical landfill slope. The MSW dump is divided into three layers for calculation. The blue dashed lines show the water levels for the precipitation scenarios during two return periods (50 and100 years).
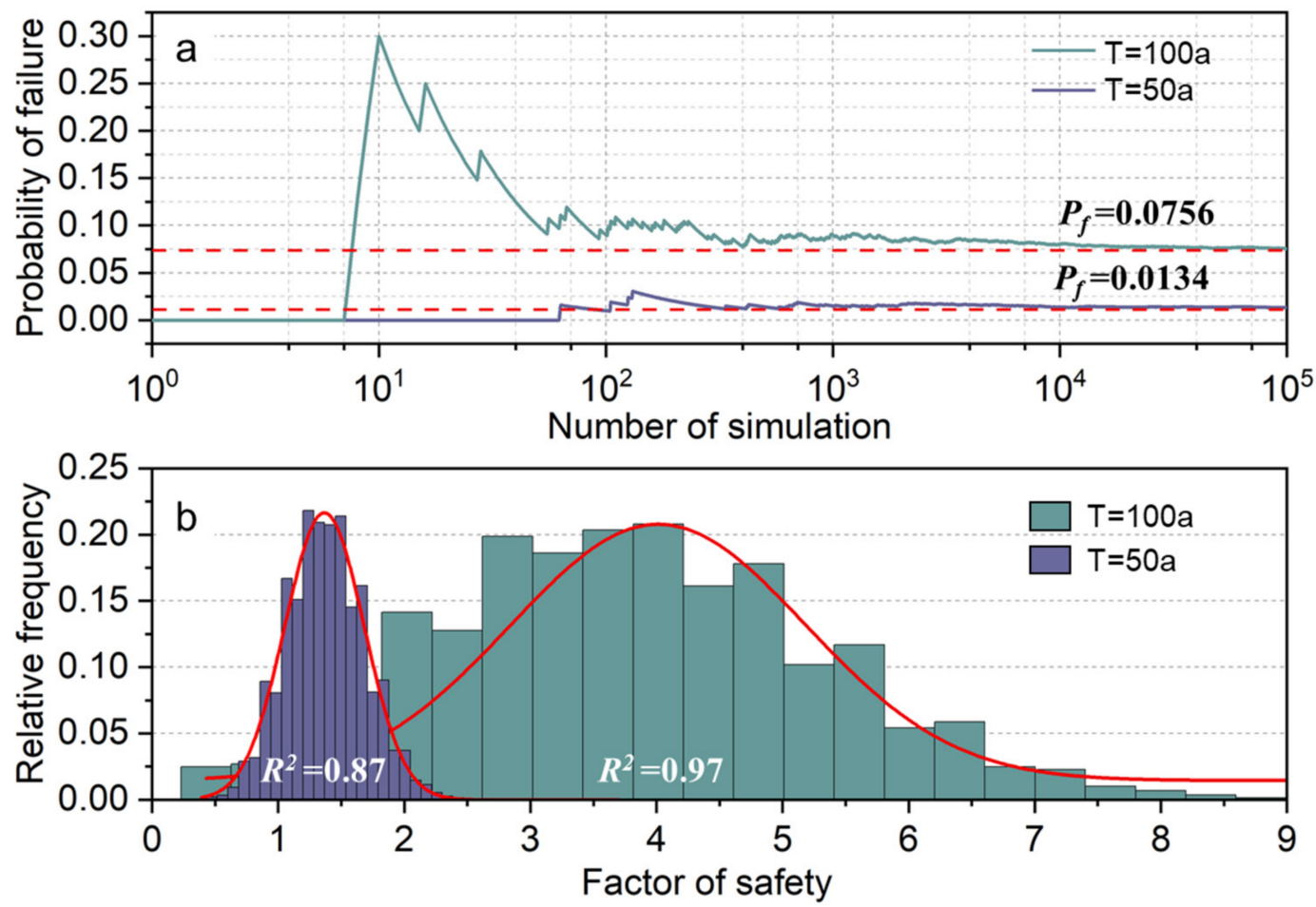

Figure 13. Monte Carlo simulation results under two rainfall conditions: (a) average failure probability vs. number of simulations; (b) histogram of the safety factor.

\subsubsection{Determination of Temporal Probability $\left(P_{T: L}\right)$ and Spatial Probability $\left(P_{S: T}\right)$}

The hazard associated with landfill failure may cause significant risk if there is a consequence arising from the failure. Thus, the quantitative estimation of post-failure motion is vital. For a run-out distance estimation, an empirical model was developed based on the historical landfill failure events:

$$
\frac{H}{L}=A V^{B}
$$

where $H$ is the elevation difference of the dumpsite, $L$ is the run-out distance, $V$ is the sliding dump volume, and $\Delta L$ is the travel difference between $L$ and $L_{0}$ (Figure 14). A positive $\Delta L$ value indicates that the landfill waste flow will bury the people at risk. Parameters A and B were obtained by comparing the landfill failure accidents mentioned in Table 1, valued 
at 9.2359 and -0.2864 , respectively. The longitudinal section area of the most dangerous profile was calculated according to the previous analysis. Based on the monitoring results, we assumed that the width of the sliding dump followed the normal distribution, with a mean value of $350 \mathrm{~m}$ and COV of $0.15 \mathrm{~V}$, which were calculated by multiplying the area of the profile and the width of the sliding dump. The area where the at-risk element was located was divided into two zones, zone $a$ and zone $b$, according to the aggregation degree of the buildings (Figure 15). The distances from the source area of landfill failure to the boundary lines of zone $a$ and zone $b$ were 350 and $700 \mathrm{~m}$, respectively, which could be used as thresholds to indicate where MSW flow could affect human life. We assumed that human life in the whole zone would be affected once the run-out distance exceeded the corresponding threshold (Figure 14). The elevation difference was $60 \mathrm{~m}$. The Monte Carlo simulation was used to determine the $P_{T: L}$.

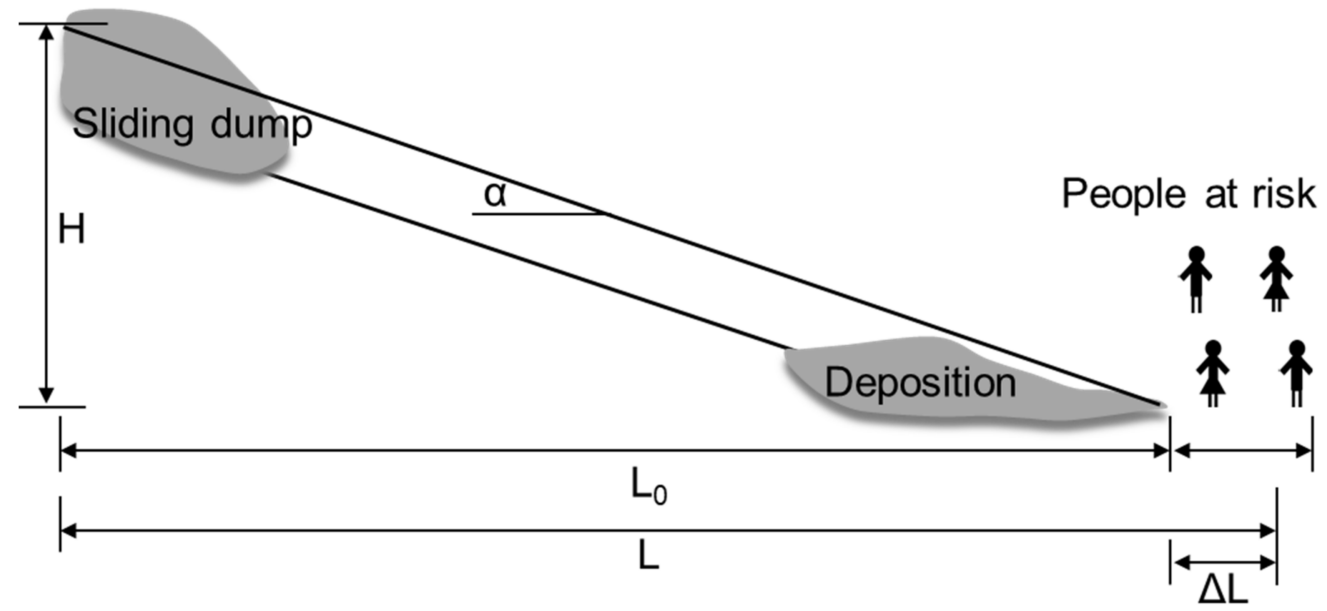

Figure 14. Run-out distance of landfill waste flow.

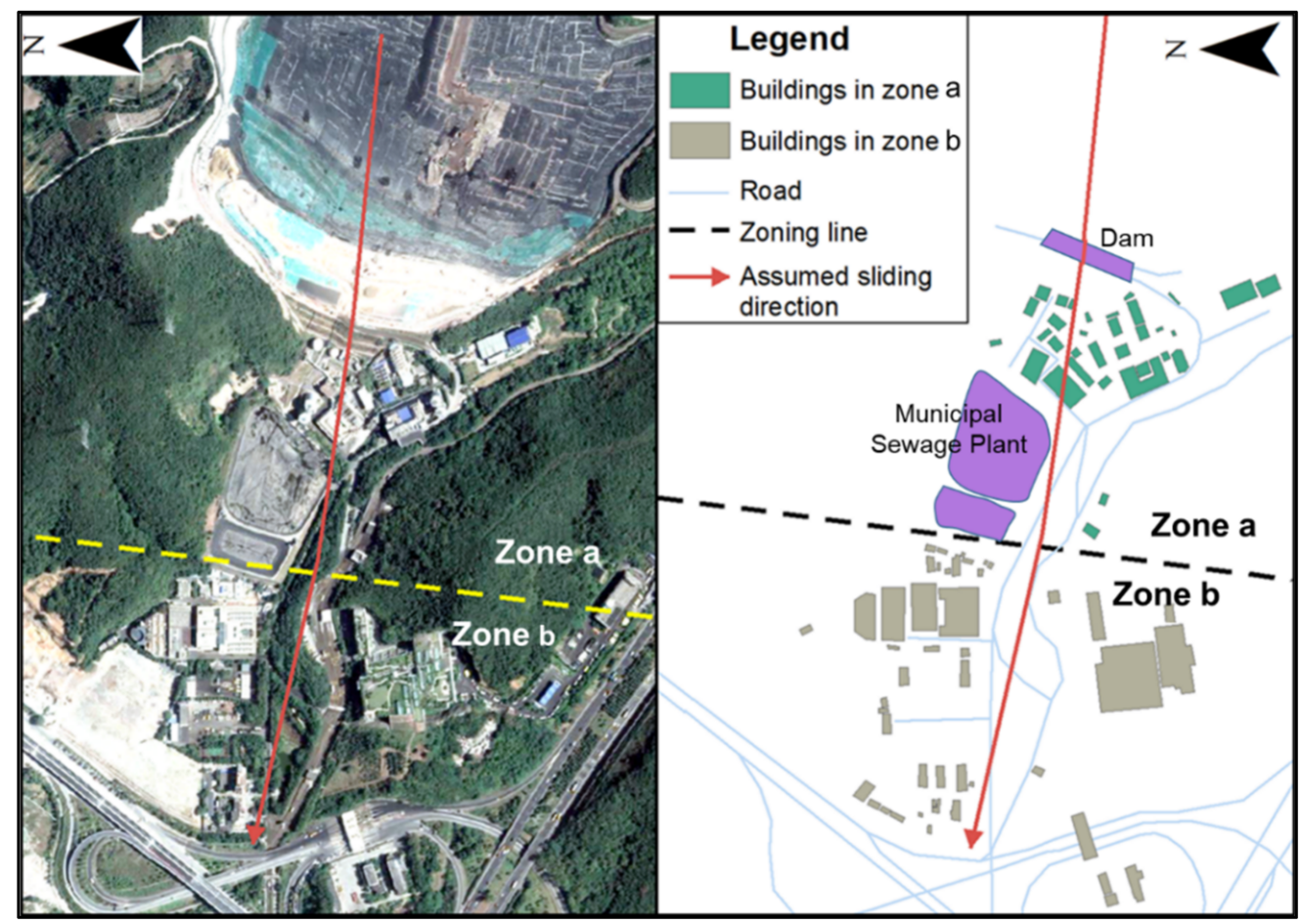

Figure 15. Distribution of elements in the study area. Zone a is used for production management, while Zone $b$ is used for office and living areas. 
The calculation of $P_{S: T}$ was mainly based on the analysis of working hours. A survey showed that most of the industrial workers begin their work at 8:00 a.m. and get off work at 7:00 p.m. According to the Ministry of Labor and Social Security of the People's Republic of China, the statutory holidays in China amount to 11 days and weekends amount to 104 days. The $P_{S: T}$ during the daytime was $10 / 24 \times 250 / 365=28.54 \%$, while the $P_{S: T}$ at night was $1 / 24 \times 250 / 365=2.85 \%$.

\subsubsection{Consequence Analysis}

The element at risk was taken as the people that may be buried by the waste flow [21], which can be calculated as:

$$
E=\frac{A}{D}
$$

where $A$ is the area of the buildings and $D$ is the population density of the buildings.

The total number of buildings in the study area was identified based on remote sensing images (Figure 15). Thirty-three buildings covering an area of $14,618 \mathrm{~m}^{2}$ in zone A and 46 buildings covering an area of $35,188 \mathrm{~m}^{2}$ in zone B constituted the total construction area. The population density of the industrial buildings was 28,000 people per $\mathrm{km}^{2}$ according to on-site interviews. The elements at risk in zone $\mathrm{a}$ and zone $\mathrm{b}$ also conformed to the normal distribution, with mean values of 818 and 1970, respectively. Considering the variability of vulnerability of the two zones and referring to the relevant literature [34-36], the vulnerability was assumed to follow the normal distribution, the mean values of which were assumed to be 0.8 and 0.3 , corresponding to zone a and zone $b$, while the COV values of both zones were assumed to be 0.1 .

\subsubsection{Risk Calculation}

According to the hazard and consequence analysis, the QRA can be implemented according to Equations (1) and (2). The results for the societal risk and individual risk of landfill failure are graphically presented in Figure 16. For the 50-year storm scenario, the average individual risk during the daytime was 0.0031 and the average societal risk value was 2.5. Correspondingly, at nighttime, the average individual risk was $3.05 \times 10^{-4}$ and the average societal risk was 0.25 . For the 100 -year storm scenario, the average individual risk during the daytime was 0.017 and the average societal risk value was 14.12, while at nighttime the average individual risk was 0.0017 and the average societal risk was 1.41. The societal risks and individual risks are also summarized in Table 7.

Table 7. Societal and individual risks during daytime and nighttime under two precipitation scenarios.

\begin{tabular}{cccccc}
\hline \multirow{2}{*}{ Precipitation Scenario } & \multicolumn{2}{c}{$\boldsymbol{R}_{\boldsymbol{D L}}$ (Individual Risk) } & \multicolumn{2}{c}{$\boldsymbol{R}_{\boldsymbol{L O L}}$ (Societal Risk) } \\
\cline { 3 - 6 } & Daytime & Nighttime & Daytime & Nighttime \\
\hline \multirow{3}{*}{$\mathrm{T}=50 \mathrm{a}$} & Min & $2.66 \times 10^{-3}$ & $2.75 \times 10^{-4}$ & 2.20 & 0.22 \\
& Max & $3.37 \times 10^{-3}$ & $3.39 \times 10^{-4}$ & 2.79 & 0.28 \\
& Mean & $3.06 \times 10^{-3}$ & $3.05 \times 10^{-4}$ & 2.50 & 0.25 \\
\hline \multirow{2}{*}{$\mathrm{T}=100 \mathrm{a}$} & Min & 0.015 & $1.52 \times 10^{-3}$ & 12.47 & 1.25 \\
& Max & 0.019 & $1.91 \times 10^{-3}$ & 16.01 & 1.58 \\
& Mean & 0.017 & $1.72 \times 10^{-3}$ & 14.12 & 1.41 \\
\hline
\end{tabular}



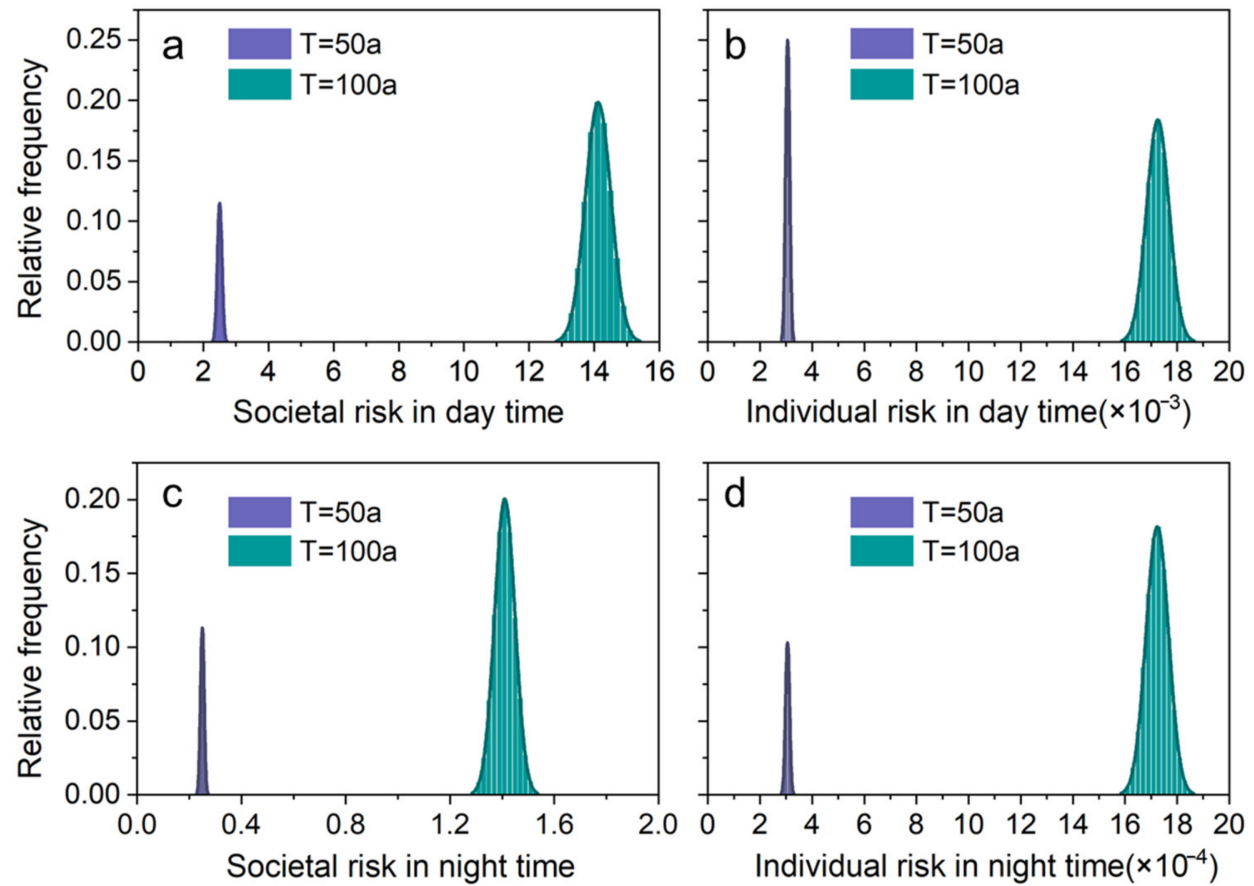

Figure 16. Societal risk and individual risk results under the two precipitation scenarios (return periods of 50 and 100 years): (a) societal risk in day time; (b) individual risk in day time; (c) societal risk in night time; (d) individual risk in night time.

\subsubsection{Risk Management}

The societal risks of landfill failure are also presented in an F-N curve, which was used to express the risk and evaluate the acceptability. Regions of acceptable, as low as practicably reasonable (ALAPR), and unacceptable risk were defined using the F-N curve method, which provided additional information on the full range of credible fatal scenarios and the corresponding likelihood of occurrence [21]. A societal risk acceptance criterion for Hangzhou landfill was proposed based on the method used by Fell [37] and using statistical data [38-40], as shown in Table 8. The median probability of death was used as the benchmark mean of acceptable risk criteria, the value of which was $10^{-5}$. The region of acceptable risk was 2 orders of magnitude smaller than the unacceptable region. It could be inferred according to the benchmark mean of acceptable risk that the upper and lower limits of the ALAPR region were $10^{-4}$ and $10^{-6}$, respectively. This shows that the hazard was in the unacceptable region (Figure 17). A comparison of the two conditions quantitatively revealed the adverse impacts of rainfall on landfill risk. Relevant mandatory precautions must be taken to reduce risk under extreme rainfall scenarios.

Table 8. Deaths caused by industrial and mining accidents in Hangzhou from 2013 to 2020.

\begin{tabular}{cccc}
\hline Year & Fatalities & Registered Residents $/ \times \mathbf{1 0}^{\mathbf{4}}$ & Probability of Death $/ \times \mathbf{1 0}^{-\mathbf{5}}$ \\
\hline 2013 & 89 & 707 & 1.26 \\
2014 & 72 & 716 & 1.01 \\
2015 & 75 & 724 & 1.04 \\
2016 & 107 & 736 & 1.45 \\
2017 & 85 & 754 & 1.13 \\
2018 & 54 & 774 & 0.70 \\
2019 & 30 & 795 & 0.38 \\
2020 & 33 & 823 & 0.40 \\
\hline
\end{tabular}






Figure 17. F-N curves for Tianziling landfill after the dump failure. The risk used in the figure was the average value.

\section{Discussion}

As newly developed monitoring techniques, InSAR and UAV photogrammetry have shown many advantages in terms of the monitoring scale and working efficiency, while conventional ground-based surveys remain important for validating the above two techniques. Ground measurements are of relatively high accuracy but poorly perceive the macro-scale deformations of landfills. The vertical displacement can be measured using UAV photogrammetry for the overall scale, while the horizontal deformation cannot be measured. The InSAR technique can be used to measure the LOS deformation with components in both vertical and horizontal directions. However, the detection accuracy of InSAR is affected by complex environmental factors such as weather, terrain, and vegetation. The transformation of the single-source InSAR deformation geometry is based on the assumption that the deformation in the other direction is 0 , ignoring the north-south deformation and deformation of directions other than the projected one when conducting two-dimensional projections. This only shows the correlation between LOS deformation and deformation in vertical and east-west directions.

Only human risks were quantified using QRA, considering two precipitation return periods (50 and 100 years). The spatial variability considered in the analysis of the probability of failure and reliability of MSW landfill slopes ignored the spatial variability of properties of leachate and landfill gas. The rainfall-induced landfill failure was considered under the condition that the ground water table reached the surface of the dump, the result of which was relatively conservative.

The InSAR technique, UAV photogrammetry, and ground measurements are quite commonly used for natural geological hazards such as volcanic activities, earthquakes, and landslides [6-12,15-18,25,41]. The individual or combined operation of these technologies has also been applied in urban settlement monitoring $[6,42,43]$ and relatively stable landfill deformation monitoring $[18,44]$. However, the ISUGS approach had never been used for 
landfills in operation due to problems of low spatiotemporal relativity, data verification, and joint solution of site deformation. It is necessary to combine the satellite, $\mathrm{UAV}$, and ground techniques to characterize the deformation of landfills in operation and to explore this joint application method for risk identification and assessment.

\section{Conclusions}

Quantitative risk assessments (QRAs) for landfills are important in reducing the human risk posed by potential landfill failures due to extreme rainfall. A comprehensive QRA method combined with an integrated satellite-UAV-ground survey (ISUGS) approach was proposed in this study, which provided a complete set of ideas and methods for risk management. It was demonstrated that the ISUGS approach could fulfil the site monitoring and QRA requirements of the landfill. The conclusions are summarised as follows:

(1) Deformation from millimeters to meters was detected and analyzed using the satellite-UAV-ground survey approach. Ground measurements showed that the net deformation velocity and accumulative deformation of the waste dump exceeded $10 \mathrm{~mm} / \mathrm{d}$ and $8 \mathrm{~m}$ at the monitoring point, respectively. The InSAR results, at the macro scale, highlighted the active movements in the areas where MSW was dumped and sludge pits were underneath, with a maximum displacement rate of $-72 \mathrm{~mm} /$ year detected along the line of sight direction. The deformation projection showed different correlations between the vertical and east-west deformation components in the LOS direction in different areas of the landfill. Focusing on the uplift and subsidence, the UAV photogrammetry results revealed the migration of MSW materials from dumping areas to the downstream areas by comparing the elevation increases and decreases at the site. Although having different measurable ranges and spatiotemporal relativity values, the satellite-UAV-ground survey results matched well with each other in terms of the deformation trends, showing the mutual verifiability between them for landfill monitoring. Water and sludge can change the rheology and compression characteristics of MSW, contributing to the deformation of the landfill and causing instability. The deformation gradient of the landfill body had a certain temporal lag of about a month compared to the period of peak rainfall.

(2) A QRA method considering the uncertainty in causes and consequences was proposed as a tool for failure probability assessments of MSW landfills by integrating multisource ISUGS data, which allowed the identification of unstable areas and provided the deformation characteristics used for the risk estimation. The F-N curve with modified parameters suitable for Hangzhou was proposed, whereby the upper and lower limits of the ALAPR region were $10^{-4}$ and $10^{-6}$, respectively. Under precipitation conditions and a 50 -year return period, the societal risks during daytime and nighttime were 2.5 and 0.25 , while the individual risks were 0.0031 and $3.05 \times 10^{-4}$, respectively. Under precipitation conditions and a 100-year return period, the societal risks during daytime and nighttime were 14.12 and 1.41 , while the individual risks were 0.017 and 0.0017 , respectively. Risks reflected in the F-N curve showed that the hazards under the above two precipitation circumstances were unacceptable. Precautions are necessary in landfill risk management.

Author Contributions: Conceptualization, S.Z. and Y.C.; methodology, S.Z. and Y.L.; software, Y.L.; validation, Y.H.; formal analysis, L.Z. and B.B.; investigation, Y.L. and J.P.; resources, Y.C.; data curation, J.L. and Y.H.; writing-original draft preparation, Y.L.; writing-review and editing, S.Z.; visualization, Y.L. and J.P.; supervision, J.L. and L.Z.; project administration, H.Y.; funding acquisition, B.B. All authors have read and agreed to the published version of the manuscript.

Funding: This study was funded by the National Key R\&D Program of China (Grant Nos. 2019YFC 1806001, 2018YFC1802301) and the Young Scientists Fund of the National Natural Science Foundation of China (Grant No. 41907243).

Institutional Review Board Statement: Not applicable.

Informed Consent Statement: Not applicable.

Data Availability Statement: Not applicable. 
Conflicts of Interest: The authors declare no conflict of interest.

\section{References}

1. Troschinetz, A.M.; Mihelcic, J.R. Sustainable recycling of municipal solid waste in developing countries. Waste Manag. 2009, 29, 915-923. [CrossRef]

2. Zhan, L.T.; Xu, H.; Chen, Y.M.; Lan, J.W.; Lin, W.A.; Xu, X.B.; He, P.J. Biochemical, hydrological and mechanical behaviors of high food waste content MSW landfill: Liquid-gas interactions observed from a large-scale experiment. Waste Manag. 2017, 68, 307-318. [CrossRef]

3. Chen, Y.M.; Ke, H.; Fredlund, D.G.; Zhan, L.T.; Xie, Y. Secondary Compression of Municipal Solid Wastes and a Compression Model for Predicting Settlement of Municipal Solid Waste Landfills. J. Geotech. Geoenvironmental Eng. 2010, 136, 706-717. [CrossRef]

4. Jahanfar, A.; Amirmojahedi, M.; Gharabaghi, B.; Dubey, B.; McBean, E.; Kumar, D. A novel risk assessment method for landfill slope failure: Case study application for Bhalswa Dumpsite, India. Waste Manag. Res. 2017, 35, 220-227. [CrossRef]

5. Dai, K.R.; Li, Z.H.; Tomas, R.; Liu, G.X.; Yu, B.; Wang, X.W.; Cheng, H.Q.; Chen, J.J.; Stockamp, J. Monitoring activity at the Daguangbao mega-landslide (China) using Sentinel-1 TOPS time series interferometry. Remote Sens. Environ. 2016, 186, 501-513. [CrossRef]

6. Fiaschi, S.; Holohan, E.P.; Sheehy, M.; Floris, M. PS-InSAR Analysis of Sentinel-1 Data for Detecting Ground Motion in Temperate Oceanic Climate Zones: A Case Study in the Republic of Ireland. Remote Sens. 2019, 11, 348. [CrossRef]

7. Papageorgiou, E.; Foumelis, M.; Trasatti, E.; Ventura, G.; Raucoules, D.; Mouratidis, A. Multi-Sensor SAR Geodetic Imaging and Modelling of Santorini Volcano Post-Unrest Response. Remote Sens. 2019, 11, 259. [CrossRef]

8. Refice, A.; Spalluto, L.; Bovenga, F.; Fiore, A.; Miccoli, M.N.; Muzzicato, P.; Nitti, D.O.; Nutricato, R.; Pasquariello, G. Integration of persistent scatterer interferometry and ground data for landslide monitoring: The Pianello landslide (Bovino, Southern Italy). Landslides 2019, 16, 447-468. [CrossRef]

9. Tzouvaras, M.; Kouhartsiouk, D.; Agapiou, A.; Danezis, C.; Hadjimitsis, D.G. The Use of Sentinel-1 Synthetic Aperture Radar (SAR) Images and Open-Source Software for Cultural Heritage: An Example from Paphos Area in Cyprus for Mapping Landscape Changes after a 5.6 Magnitude Earthquake. Remote Sens. 2019, 11, 1766. [CrossRef]

10. Wasowski, J.; Pisano, L. Long-term InSAR, borehole inclinometer, and rainfall records provide insight into the mechanism and activity patterns of an extremely slow urbanized landslide. Landslides 2020, 17, 445-457. [CrossRef]

11. Intrieri, E.; Raspini, F.; Fumagalli, A.; Lu, P.; Del Conte, S.; Farina, P.; Allievi, J.; Ferretti, A.; Casagli, N. The Maoxian landslide as seen from space: Detecting precursors of failure with Sentinel-1 data. Landslides 2018, 15, 123-133. [CrossRef]

12. Prasad, K.A.; Ottinger, M.; Wei, C.; Leinenkugel, P. Assessment of Coastal Aquaculture for India from Sentinel-1 SAR Time Series. Remote Sens. 2019, 11, 357. [CrossRef]

13. Liu, G.X.; Ding, X.L.; Li, Z.L.; Li, Z.W.; Chen, Y.Q.; Yu, S.B. Pre- and co-seismic ground deformations of the 1999 Chi-Chi, Taiwan earthquake, measured with SAR interferometry. Comput. Geosci. 2004, 30, 333-343. [CrossRef]

14. Wasowski, J.; Bovenga, F. Investigating landslides and unstable slopes with satellite Multi Temporal Interferometry: Current issues and future perspectives. Eng. Geol. 2014, 174, 103-138. [CrossRef]

15. Dai, C.; Li, W.L.; Wang, D.; Lu, H.Y.; Xu, Q.; Jian, J. Active Landslide Detection Based on Sentinel-1 Data and InSAR Technology in Zhouqu County, Gansu Province, Northwest China. J. Earth Sci. 2021, 32, 1092-1103. [CrossRef]

16. Rossi, G.; Tanteri, L.; Tofani, V.; Vannocci, P.; Moretti, S.; Casagli, N. Multitemporal UAV surveys for landslide mapping and characterization. Landslides 2018, 15, 1045-1052. [CrossRef]

17. Shi, B.Q.; Liu, C. UAV for Landslide Mapping and Deformation Analysis. In Proceedings of the International Conference on Intelligent Earth Observing and Applications 2015, Guilin, China, 23-24 October 2015; Volume 9808, p. 98080P.

18. Baiocchi, V.; Napoleoni, Q.; Tesei, M.; Servodio, G.; Alicandro, M. UAV for monitoring the settlement of a landfill (October, 10.1080/22797254.2019.1683471, 2019). Eur. J. Remote Sens. 2019, 52, 53. [CrossRef]

19. Dai, F.C.; Lee, C.F.; Ngai, Y.Y. Landslide risk assessment and management: An overview. Eng. Geol. 2002, 64, 65-87. [CrossRef]

20. Jahanfar, A.; Dubey, B.; Gharabaghi, B.; Movahed, S. Landfill Failure Mobility Analysis: A Probabilistic Approach. World Acad. 2016, 10, 476-484.

21. Zhang, S.; Zhang, L.M.; Peng, M.; Zhang, L.L.; Zhao, H.F.; Chen, H.X. Assessment of risks of loose landslide deposits formed by the 2008 Wenchuan earthquake. Nat. Hazard. Earth Syst. Sci. 2012, 12, 1381-1392. [CrossRef]

22. ASF Data Search. Available online: https://search.asf.alaska.edu/ (accessed on 1 February 2021).

23. Berardino, P.; Fornaro, G.; Lanari, R.; Sansosti, E. A new algorithm for surface deformation monitoring based on small baseline differential SAR interferograms. IEEE Trans. Geosci. Remote Sens. 2002, 40, 2375-2383. [CrossRef]

24. Dong, J.; Liao, M.S.; Xu, Q.; Zhang, L.; Tang, M.G.; Gong, J.Y. Detection and displacement characterization of landslides using multi- temporal satellite SAR interferometry: A case study of Danba County in the Dadu River Basin. Eng. Geol. 2018, 240, 95-109. [CrossRef]

25. Meng, Q.K.; Li, W.L.; Raspini, F.; Xu, Q.; Peng, Y.; Ju, Y.Z.; Zheng, Y.Z.; Casagli, N. Time-series analysis of the evolution of large-scale loess landslides using InSAR and UAV photogrammetry techniques: A case study in Hongheyan, Gansu Province, Northwest China. Landslides 2021, 18, 251-265. [CrossRef] 
26. Wang, X.W.; Liu, G.X.; Yu, B.; Dai, K.R.; Zhang, R.; Chen, Q.; Li, Z.L. 3D coseismic deformations and source parameters of the 2010 Yushu earthquake (China) inferred from DInSAR and multiple-aperture InSAR measurements. Remote Sens. Environ. 2014, 152, 174-189. [CrossRef]

27. Australian Geomechanics Society Sub-Committee on Landslide Risk Management. Landslide Risk Management Concepts and Guidelines. Aust. Geomech. News J. Aust. Geomech. Soc. 2002, 37, 1-44. [CrossRef]

28. Morgan, G. Evaluating total risk to communities from large debris flows. In Proceedings of the 1st Canadian Symposium on Geotechnique and Natural Hazards. Geohazards-92 Symposium, Richmond, BC, Canada, 6-9 May 1992; BiTech Publishers: Richmond, BC, Canada, 1992; pp. 225-236.

29. Chen, Y.M.; Xu, X.B.; Zhan, L.T. Analysis of solid-liquid-gas interactions in landfilled municipal solid waste by a bio-hydromechanical coupled model. Sci. China Technol. Sci. 2012, 55, 81-89. [CrossRef]

30. Li, X.L.; Shi, J.Y. Stress-strain Behaviour and Shear Strength of Municipal Solid Waste (MSW). Ksce J. Civ. Eng. 2016, 20, 1747-1758. [CrossRef]

31. Raviteja, K.V.N.S.; Basha, B.M. Characterization of Variability of Unit Weight and Shear Parameters of Municipal Solid Waste. J. Hazard. Toxic Radio 2021, 25, 04020077. [CrossRef]

32. Zhan, L.T.; Luo, X.Y.; Guan, R.Q.; Zeng, X.; Lan, J.W.; Chen, Y.M.; Lin, W.A. Failure mechanism of sludge pit and downstream waste slope of a MSW landfill. Chin. J. Geotech. Eng. 2013, 35, 1189-1196.

33. Li, Z.H.; Song, L.L.; Liang, Z.R.; Wang, K.; Liu, S.F. Precipitation Characteristics and Projection of Extreme Precipitation Trend in Hangzhou City. Meteorol. Mon. 2018, 44, 781-789.

34. Luna, B.Q.; Blahut, J.; Camera, C.; van Westen, C.; Apuani, T.; Jetten, V.; Sterlacchini, S. Physically based dynamic run-out modelling for quantitative debris flow risk assessment: A case study in Tresenda, northern Italy. Env. Earth Sci. 2014, 72, 645-661.

35. Luo, H.Y.; Zhang, L.L.; Zhang, L.M. Progressive failure of buildings under landslide impact. Landslides 2019, 16, 1327-1340. [CrossRef]

36. Wong, H.; Ko, F. Landslide Risk Assessment: Application and Practice; Geotechnical Engineering Office, Civil Engineering and Development Department: Hongkong, China, 2006.

37. Fell, R. Landslide Risk Assessment and Acceptable Risk. Can. Geotech. J. 1994, 31, 261-272. [CrossRef]

38. Ministry of Housing and Urban-Rural Development of the People's Republic of China. Technical Code for Geotechnical Engineering of Municipal Solid MSW Sanitary Landfill; China Architecture Publishing \& Media Co.Ltd.: Beijing, China, 2012.

39. Hangzhou Municipal Government. Announcement of Various Safety Production and Natural Disasters in the City in 2020. Available online: http://www.hangzhou.gov.cn/art/2021/1/22/art_1229063408_3838849.html (accessed on 1 September 2021).

40. Hangzhou Bureau of Statistics. Available online: http://tjj.hangzhou.gov.cn/art/2020/10/29/art_1229453592_3819709.html (accessed on 1 September 2021).

41. Mateos, R.M.; Azañón, J.M.; Roldán, F.J.; Notti, D.; Pérez-Peña, V.; Galve, J.P.; Pérez-García, J.L.; Colomo, C.M.; Gómez-López, J.M.; Montserrat, O.; et al. The combined use of PSInSAR and UAV photogrammetry techniques for the analysis of the kinematics of a coastal landslide affecting an urban area (SE Spain). Landslides 2017, 14, 743-754. [CrossRef]

42. Yan, Y.; Doin, M.-P.; Lopez-Quiroz, P.; Tupin, F.; Fruneau, B.; Pinel, V.; Trouve, E. Mexico City Subsidence Measured by InSAR Time Series: Joint Analysis Using PS and SBAS Approaches. IEEE J. Sel. Top. Appl. Earth Obs. Remote Sens. 2012, 5, 1312-1326. [CrossRef]

43. Emil, M.; Sultan, M.; Alakhras, K.; Sataer, G.; Gozi, S.; Al-Marri, M.; Gebremichael, E. Countrywide Monitoring of Ground Deformation Using InSAR Time Series: A Case Study from Qatar. Remote Sens. 2021, 13, 702. [CrossRef]

44. Baek, W.K.; Jung, H.S.; Jo, M.J.; Lee, W.J.; Zhang, L. Ground subsidence observation of solid waste landfill park using multitemporal radar interferometry. Int. J. Urban Sci. 2019, 23, 406-421. [CrossRef] 